\title{
Relative Performance of Strawberry Genotypes on Fumigated and Nonfumigated Soils
}

\author{
Kirk D. Larson \\ University of California South Coast Research and Extension Center, 7601 Irvine Boulevard, Irvine, \\ CA 92718
}

\author{
Douglas V. Shaw \\ Department of Pomology, University of California, Davis, CA 95616
}

Additional index words, breeding, chloropicrin, Fragaria $\times$ ananassa, genotype $\times$ environment interaction, methyl bromide. soil fumigation, trichloronitromethane, vegetative growth, yield

\begin{abstract}
Performance characteristics for 12 strawberry genotypes (Fragaria xananassa Duch.) from the Univ. of California, Davis, strawberry improvement program were evaluated in annual hill culture, with and without preplant soil fumigation using a mixture of 67 methyl bromide :33 chloropicrin (trichloronitromethane) (wt/wt, 392 kg·ha ${ }^{-1}$ ). Plants were established at two locations; one trial followed several cycles of strawberry plantation, whereas the other had not been cropped with strawberries for 20 years. Plant mortality was <3\% and did not differ between soil treatments; thus, the main effects of fumigation treatment in these experiments were due to sublethal effects of soil organisms. Plants grown in nonfumigated soil produced $51 \%$ and $57 \%$ of the fruit yield of plants grown in fumigated soil for soils with and without a recent history of strawberry cultivation, respectively. Nonfumigated treatments also had reduced fruit weight and uniformly lower vegetative vigor during the early phases of plantation establishment. Significant genotype $x$ fumigation interactions were not detected for any of the growth or performance traits at either location. Further, the proportion of variance attributable to interactions was at most $25 \%$ of that due to variation among genotypes, even for this highly selected population. Genotypic correlations for traits evaluated in different fumigation treatments ranged from 0.80 to 1.00; thus, selection in either soil environment is expected to affect largely the same sets of genes. These results demonstrate that strawberry productivity is substantially increased by fumigation, even in the absence of lethal pathogens or a discernible replant problem. More importantly, there appears to be little opportunity for developing cultivars specifically adapted to sublethal effects of nonfumigated soils.
\end{abstract}

Experiments conducted over the past 50 years have demonstrated the benefits of preplant soil fumigation for strawberry productivity (Himelrick and Dozier, 1991; Wilhelm et al., 1974; Wilhelm and Paulus, 1980). Fumigation with combinations of methyl bromide and chloropicrin (trichloronitromethane) mitigates a number of production problems, including weeds, nematodes, and soilborne plant pathogenic fungi (Wilhelm and Paulus, 1980 ) and is a standard practice in highly productive strawberry production regions worldwide (Voth and Bringhurst, [990).

In general, the yield and growth response of strawberries to soil fumigation can be attributed to two sources: 1) reduced plant mortality due to control or elimination of lethal pathogens and 2) increased plant vigor due to the reduction of a highly variable complex of sublethal or-competitive soil microorganisms (Wilhelm, 1966; Wilhelm and Paulus, 1980). Although the control of specific lethal pathogens and general plant invigoration have been documented in strawberry ( Wilhelm, 1965; Wilhelm et al., 1969, 1972; Yuen et al., 1991), the relative importance of these two sources is not well established. Further, although both sources are important, nearly all investigations of genetic alternatives to fumigation have concentrated on resistance to identifiable lethal pathogens (Galletta et al., 1989), and the consequences of nonspecific, growth-limiting factors have been largely ignored (Wilhelm and Nelson. 1970).

Development of cultivars specifically adapted to nonfumigated soils is commonly cited as a potential alternative to soil cultural treatments (U.S. Dept. of Agriculture, 1993; Watson et al., 1992). In this context, the relative importance of lethal and nonspecified

Received for publication 28 June 1994. Accepted for publication 22 Aug. 1994. The cost of publishing this paper was defrayed in part by the payment of page charges. Under postal regulations, this paper therefore must he hereby marked advertisement solely to indicate this fact. sources of fumigation response and the inheritance or expression of resistance have critical implications for cultivar improvement. Soils treated differently represent substantially different production environments, and there is no reason a priori to assume similar relative responses for individual genotypes in these environments. Genotype $\times$ environment interactions are common when the environment of concern is the presence or absence of an important pathogen (Baker, 1988) and, in combination with discrete resistance classics, may lead to large shifts in performance rank. Discrete resistance classes have not been documented for major strawberry soil pathogens, but shifts in performance rank might be expected if quantitative variation for tolerance among genotypes is large. Also, the extent to which major pathogen resistance is genetically correlated with a nonspecific plant growth response will determine the optimal breeding and selection strategies.

The primary objective of our study was to compare growth and yield of selected strawberry genotypes in response to different soil fumigation treatments in the absence of identifiable lethal soilborne pathogens. Our focus here was to evaluate the correspondence in performance across differing environments and the resulting consequences for breeding and selection procedures.

\section{Materials and Methods}

Plant growth and fruit yield trials were established at two locations: the Univ. of California, Watsonville, Strawberry Research Facility in central coastal California and the Univ. of California South Coast Research and Extension Center, Irvine, in southern coastal California. The Watsonville plantation was established on soil that had been cropped in strawberry in alternate years during the past 12 years. Each of the six previous strawberry production cycles was preceded by a cover crop of barley (Hordeum 
Table 1. Expected mean squares for analysis of variance of five growth and productivity traits in two strawberry fumigation trials.

\begin{tabular}{lcc}
\hline \hline Source & df & Expected mean squares \\
\hline Replication $(\mathrm{R})$ & 1 & $\sigma^{2}+24 \sigma^{2}$ \\
Fumigation $(\mathrm{F})$ & 1 & $\sigma^{2}+2 \sigma^{2}+4 \sigma_{1}^{2}$ \\
Genotype $(\mathrm{G})$ & 11 & $\sigma^{2}+2 \sigma^{2}+4 \sigma^{2}$ \\
$\mathrm{~F} \times \mathrm{G}$ & 11 & $\sigma^{2}+2 \sigma^{2}$ \\
Error & 23 & $\sigma^{2}$ \\
\hline
\end{tabular}

vulgare L.) and fava bean (Vicia faba L.), and strawberries were grown with preplant soil fumigation using a (wt/wt) mixture of 67 methyl bromide: 33 chloropicrin at a rate of $392 \mathrm{~kg} \cdot \mathrm{ha}^{-1}$. The Irvine trials were established on soil that had not been cropped in strawberries for- 20 years: at this site. recent cropping history included alfalfa (Medicago sativa L.), beans (Phaseolus vulgaris L.), and barley. Although cropping history is confounded here with location effects, comparison of results across sites will provide an indication of whether the benefits of fumigation are specific to a strawberry replant situation.

Runner plants from 12 strawberry genotypes were harvested from a propagation nursery near MacDoel, Calif., on 15 Oct. 1992 and planted in experimental plots at both locations on 21 Oct. The 12 genotypes were chosen from the 50 most advanced selections available from Univ. of California strawberry improvement program. Five of the genotypes were cultivars of current importance ('Chandler', 'Cuesta', 'Irvine'. 'Seascape', 'Sunset') and seven were advanced selections. These genotypes were chosen based on their minimum coancestry using SAS'S Inbreed procedure (SAS, 1988). The objective here was to evaluate a broad range of currently available germplasm. Four of the genotypes were dayneutral and the remainder were extended-fruiting short-day types with a range of production patterns.

Trials were established at each location and treated according to recommendations for-commercial winter plantings ( Welch, 1989). To compare fumigation treatments, adjacent parcels were prepared for planting and either treated with a mixture of 67 methyl bromide : 33 chloropicrin $\left(392 \mathrm{~kg} \cdot \mathrm{ha}^{-1}\right)$ or left untreated. Each treatment was replicated twice, with a single plot of 20 plants per genotype in each replicate. Experimental plots at Watsonville were established on two-row diagonal beds on 132-cm centers and a 36$\mathrm{cm}$ in-row plant spacing $(42,582 \mathrm{plants} / \mathrm{ha})$, whereas plots at Irvine used two-row diagonal beds on $122-\mathrm{cm}$ centers and a $41-\mathrm{cm}$ in-row plant spacing (40,363 plants/ha).

Compared to fumigation, nonfumigation resulted in greater weed populations, particularly at the Irvine site. To reduce any competitive effects of weeds, all weeds were removed by hand at monthly intervals from all plots at both sites.

Fruit yield and a 10-fruit weight were recorded weekly for 18 and 23 consecutive weeks at Irvine and Watsonville, with harvest initiating on 29 Jan. and 14 Mar., respectively. Total yield was evaluated for each plot on a per-plant basis. and fruit size was calculated as the weighted average of the 10-fruit weights obtained weekly throughout the season, with weighting based on corresponding weekly yield. To evaluate early vegetative growth, leaf numbers per plant were obtained on 1 and 12 Dec. for the Watsonville and Irvine trials, respectively. Vegetative growth during the winter was evaluated using leaf numbers and crosssectional plant diameters (Shaw, 1992) obtained on 3 and 12 February for the Watsonville and Irvine sites, respectively. Large scale differences were generated by the fumigation treatments for fruit yield, and an appropriate power transformation was performed before further analyses (Fcernandez,1992).

Preliminary imatyscs indicated significant genotype $\times$ location interactions, so analysis of variance (ANOVAs) were conducted separately by location for all traits with fumigation treatment and replications as fixed effects and genotypes as random effects, using SAS's GLM procedure (SAS, 1988). Significance tests were performed using type III expected mean squares (Table 1). Because the genotypes included in the study were initially selected at Watsonville, the genotype $\times$ location interactions observed may result from adaptation to specific environmental conditions. However, the developmental state of the plant changes rapidly in these plantations and interactions might be due to the slight differences in the timing of measurement as well.

Model variance components due to genotypes $\left(\sigma_{g}^{2}\right)$, genotype $\mathrm{x}$ fumigation treatment interaction $\left(\sigma_{\mathrm{fg}}^{2}\right)$. and Error $\left(\sigma^{2}\right)$ were estimated by equating the expected mean squares in Table 1 with their corresponding experimental mean squat-es and solving this series of linear equations. The extent to which the experimental phenotypic variance was explained by genetic differences was quantified as the experimental repeatability:

$\mathrm{R}=\sigma_{\mathrm{g}}^{2} / \sigma_{\mathrm{g}}^{2}+\sigma_{\mathrm{fg}}^{2}+\sigma^{2}$

Repeatability. R, in Eq. [1] is analogous to a genotype-tnean heritability. except that genetic components of variance are esti mated for a population that has been highly selected and not recombined (Shaw, 1992). The similarity of genotypic responses over the two fumigation treatments was quantified by treating individual traits in differing fumigation treatments as separate but genetically correlated and estimating their gcnotypic correlation as (Burden, 1977)

Table 2. Means and standard deviations for five strawberry growth and productivity traits with two fumigation treatments at two locations.

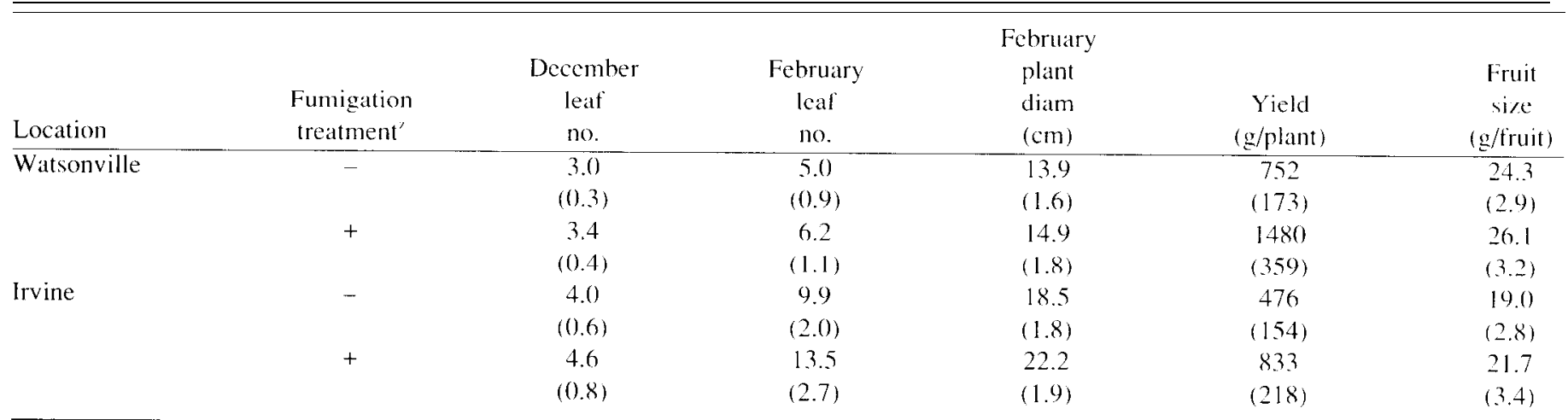

$\overline{\overline{ }}(-)$ and (+) indicate no soil fumigation and preplant soil fumigation with $392 \mathrm{~kg} \cdot \mathrm{ha}^{-1}$ of 67 methylbromide :33 chloropicrin (wt/wt). rcspectively; $\mathrm{N}=24$ for all treatments means (twelve genotypes with two replications each). 


\begin{tabular}{|c|c|c|c|c|c|}
\hline \multirow[b]{4}{*}{ Source } & \multicolumn{5}{|c|}{ Mean squares } \\
\hline & December & February & February & & \\
\hline & leaf & leaf & plant & & Fruit \\
\hline & no. & no. & diam & Yield & size \\
\hline Replication (R) & $16.30^{*}$ & 1. $20^{*}$ & $5.07 *$ & 0.70 & 0.89 \\
\hline Fumigation (F) & $140.10^{* *}$ & $10.90^{* *}$ & $13.65^{*}$ & $541.10^{* *}$ & $38.05^{* *}$ \\
\hline Genotype (G) & 35.80 & 2.70 & $8.29 * *$ & 31.50 & $32.85^{* *}$ \\
\hline$F \times G$ & 4.30 & 0.30 & 1.62 & 1.40 & 2.45 \\
\hline Error & 3.50 & 0.25 & 0.77 & 1.30 & 1.38 \\
\hline$\sigma^{2}$ & 7.90 & 0.60 & 1.67 & 7.50 & 7.61 \\
\hline$\sigma_{\mathrm{fg}}^{2}$ & 0.20 & 0.03 & 0.43 & 0.10 & 0.53 \\
\hline$r_{g y}$ & 0.98 & 0.95 & 0.80 & 0.99 & 0.93 \\
\hline$R$ & 0.68 & 0.69 & 0.58 & 0.85 & 0.80 \\
\hline
\end{tabular}

$r_{\mathrm{g} y}=\sigma_{\underline{\underline{g}}}^{2} / \sigma^{2}+\sigma^{2}$

This genotypic correlation can be used to predict the correspondence in genetic selection response where selection is performed with one fumigation treatment and performance is tested in the other.

\section{Results and Discussion}

Plant mortality at both locations was $<3 \%$, was observed only during the initial establishment phase of the plantations, and did not differ between fumigation treatments (data not shown). Thus, the main effects of fumigation treatment in these experiments was the result of sublethal and/or competitive effects of soil organisms.

Preplant soil fumigation resulted in increased plant growth, productivity, and fruit weight for all genotypes at both locations (Table 2). Fumigation response was first apparent as increased numbers of leaves per plant in December, 6 to 8 weeks after plantation establishment. At that time, plants established in nonfumigated soils had produced $80 \%$ and $73 \%$ of the leaves of those grown in fumigated soils for the Irvine and Watsonville trials, respectively. Plant size differences were apparent in February, with reduced leaf numbers $(81 \%$ and $73 \%)$ and smaller plant diameters $(93 \%$ and $83 \%$ ) for plants in nonfumigated soils at Irvine and Watsonville, respectively. Productivity, as reflected by total yield, was the trait most affected by soil fumigation: plants grown in nonfumigated soil yielded $57 \%$ and $51 \%$ of the fruit produced by plants in adjacent fumigated soil for the Ii-vine and Watsonville trials, respectively. Plants grown in nonfumigated soils also produced smaller fruit $(93 \%$ and $88 \%$ of that of the Irvine and Watsonville fumigated trials, respectively), The large fumigation response for nearly all traits on soil that was free of strawberry production for 20 years suggests that many of the soil organisms responsible for the yield decline arc general rather than hostspecific pathogens.

The fumigation treatment effects summarized above were further evaluated using ANOVA and were significant to highly significant for all traits at both locations (Tables 3 and 4). Substantial genotypic variation was detected at both test locations, with significant to highly significant variances for all traits (Tables 3 and 4). Repeatabilities ranged from 0.36 to 0.85 , suggesting the presence of substantial genetic variation even within this highly selected sample of genotypes. Conversely, none of the genotype $x$ fumigation treatment interaction variances were significant, suggesting that the main effects of nonlethal soil organisms affected all genotypes similarly. Further, the proportion of variance attributable to interactions $\left(\sigma_{\mathrm{fg}}^{2}\right)$ was at most $26 \%$ of that due to variation among genotypes $\left(\sigma_{g}^{2}\right)$, even for this highly selected population (Table 3). As a consequence, genotypic correlations calculated by treating traits evaluated in different fumigation treatments as separate but genetically correlated ranged from $\mathrm{r}=0.80$ to 1.00 .

Together, these results demonstrate that strawberry productiv-

Table 4. Results for analysis of variance for five strawberry growth and productivity traits with two soil fumigation treatments at Irvine, Cal if.

\begin{tabular}{|c|c|c|c|c|c|}
\hline \multirow[b]{2}{*}{ Source } & \multicolumn{5}{|c|}{ Mean squares } \\
\hline & $\begin{array}{c}\text { December } \\
\text { leaf } \\
\text { no. }\end{array}$ & $\begin{array}{c}\text { February } \\
\text { leaf } \\
\text { no. }\end{array}$ & $\begin{array}{c}\text { February } \\
\text { plant } \\
\text { d i am }\end{array}$ & Yield & $\begin{array}{l}\text { Fruit } \\
\text { size }\end{array}$ \\
\hline Replication (R) & 46.00 & 2.94 & 0.27 & 0.00 & $23.08 *$ \\
\hline Fumigation (F) & $462.50 * *$ & $26.98^{* * *}$ & $168.75^{*}$ & $392.70^{* *}$ & $86.99 * *$ \\
\hline Genotype (G) & $141.40 * *$ & 7.91 & 11.93 & 20.40 & $23.21 * *$ \\
\hline $\mathrm{F} \times \mathrm{G}$ & 12.10 & 0.59 & 0.49 & 7.40 & 4.10 \\
\hline Error & 43.60 & 1.14 & 1.00 & 4.60 & 2.26 \\
\hline$\sigma^{2}$ & 24.45 & 1.69 & 2.73 & 5.70 & 4.78 \\
\hline$\sigma^{2}{ }_{f g}$ & 0.00 & 0.00 & 0.00 & 1.40 & 0.92 \\
\hline$r_{g y}$ & 1.00 & 1.00 & 1.00 & 0.80 & 0.84 \\
\hline$R$ & 0.36 & 0.60 & 0.73 & 0.49 & 0.60 \\
\hline
\end{tabular}

*,**Significant at $P=0.05$ or 0.01 , respectively; mean squares and variance components for yield and leaf numbers have been multiplied by $10^{2}$ for ease of presentation. 
ity is substantially increased by fumigation, even in the absence of lethal pathogens or an immediate replant problem. More importantly, genetic differences among the advanced selections tested here were expressed consistently across fumigated and nonfimigated soils. Our results are consistent with a growing consensus that important genotype $\times$ environment interactions in crop plants. i.e., those that confer rank shifts are largely the result of the presence or-absence of lethal pathogens with complemental-y discrete resistance categories (Baker, 1988). In the absence of shifts in performance rank. there is little expected advantage to screening of advanced selections in nonfumigated soils: testing in nonfumigated soil will express little if any added adaptational variance and can add substantial heterogeneity. Further, screening for resistance or tolerance to specific lethal pathogens is perhaps best achieved using complementary tests conducted under controlled environments.

Although our trial included a limited genetic sample, it demonstrates that little opportunity exists within the Univ. of California strawberry germplasm for developing cultivars specifically adapted to the unspecified reductions in performance commonly observed for strawberries grown in nonfumigated soils. Infusion of materials from other germplasm sources is often cited as a solution to this problem. However, although germplasm outside California have been selected for specific pathogen tolerance. growth and yield reductions in our trials were not due to any identifiable pathogen, Furthermore, when evaluated in California, the best materials obtained from outside of our program produced at most $50 \%$ of the annual yield of modem California cultivars (Rariden and Shaw, 1994), and the barriers to utilization of this germplasm in California are not expected to be trivial. There is apparently no simple solution for developing cultivars specifically adapted to sublethal effects of nonfumigated soils.

\section{Literature Cited}

Baker, R. 1988. Tests for crossover genotype+environment interactions. Can. J. Plant Sci. 68:405-410.

Burden R.D. 1977. Generic correlation as a concept for studying genotype $\times$ environment interaction in forest tree breeding. Silvae Genet. 26:168-175.

Fernandez. G.C.J. 1992. Residual analysis and data transformations: Important tools in statistical analysis. HortScience 27:297-300.
Galletta, G. J.. A.D. Draper, and J.L. Maas. 1989. Combining diseasc resistance, plant adaptation, and fruit quality in breeding short day and day-neutral strawberries. Acta Hort. 265:43-51.

Himelrick. D.G. and W.A. Dozier, 1991. Soil fumigation and soil solarizarion in strawberry production. Adv. Strawberry Prod. 10: 12-28.

Rariden, J.R. and D.V. Shaw, 1994. Performance of North American strawberry cultivars under conditions mimicking California production systems. J. Amer. Soc. Hort. Sci. 119:1034-1038.

SAS Institute. 1988. SAS/STAT users guide. release 6.03. SAS Institute. Cary, N.C.

Shaw, D.V. 1992. Genetic correlations between vegetative growth traits and productivity at different within-season intervals fur strawberries (Fragaria ×ananassa). Theoretical Applied Genet. 85:1001-1009.

U.S. Department of Agriculture. 1993. Methyl bromide substitutes and alternatives. U.S. Dept. of Agr.

Voth, V. and R.S. Bringhurst. 1990. Culture and physiological manipulation of California strawberries. HortScience 25:889-892.

Watson, R. T.. D.L. Albritton, S.O. Anderson. and S.E. Bapty. 1992. Methyl bromide: its atmospheric science. technology. and economics. Montreal Protocol Assessment Summary. United Nations Environment Program, Nairobi. Kenya.

Welch, N. 1989. Strawberry production in California. Univ. of California Coop. Ext. Lflt. 2959.

Wilhelm, S. 1965. Pythium ultimum and the soil fumigation growth response. Phytopathology 55:1016 -1020.

Wilhelm, S. 1966. Chemical treatments and innoculum potential of soil. Annu. Rev. Phytopath. 4:53-78.

Wilhelm, S. and P.E. Nelson. 1970. A concept of rootlet health of strawberries in pathogen-free field soil acheived by fumigation. In: T.A. Toussoun, R.V. Bega, and P.E. Nelson (eds.). Root diseases and soilborne pathogens. University of Calif. Press, Berkeley.

Wilhelm, S., P.E. Nelson. and D.H. Ford. 1969. A gray sterile fungus pathogenic on strawberry roots. Phytopathology 59: 1525- 1529.

Wilhelm. S., F'. E. Nelson, H.E, Thomas, and H. Johnson. 1972. Pathology of strawberry root rot caused by Ceratobasidium species. Phytopathology 62:700-705.

Wilhelm, S. and A.O. Paulus. 1980. How soil fumigation benefits [he California strawberry industry. Plant Dis. 64:264-270.

Wilhelm. S., R.C. Storkan, and J.M. Wilhelm. 1974. Preplant soil fumigation with methyl bromide-chloropicrin mixtures for control of soilborne diseases of strawberries-A summary of fifteen years of development. Agr. Environ, 1:227-236.

Yuen, G. Y., M.N. Schroth, A.R. Weinhold. and J.G. Hancock. 1991. Effects of soil fumigation with methyl bromide and chloropicrin on root health and yield in strawberry, Plant Dis. 75:416-420. 